\title{
Comparative iTRAQ proteomics identified proteins associated with sperm maturation between yak and cattleyak epididymis
}

\author{
Wangsheng Zhao', Siraj Ahmed', Junxia Liu², Saeed Ahmed', Eugene Quansah', Tajmal Hussain Solangi', \\ Yitao $\mathrm{Wu}^{1}$, Yueling Yangliu ${ }^{1}$, Hongmei Wang ${ }^{1}$, Jiangjiang $\mathrm{Zhu}^{3,4^{*}}$ and Xin Cai ${ }^{3,4^{*}}$
}

\begin{abstract}
Background: During maturation, spermatozoa acquire motility and fertilizing capacity as they transit through the epididymis. In recent years, two-dimensional gel electrophoresis has been employed in proteomics studies conducted in rat, boar and human. However, there has not been a complete information regarding the proteins associated with sperm maturation in the epididymis. In this study, we employed iTRAQ proteomics to investigate proteins associated with sperm maturation between yak and cattleyak epididymis.

Results: After a successful sampling and protein extraction, the iTRAQ coupled with LC-MS/MS mass spectrometry and bioinformatics analysis were performed. We identified 288 differentially abundant proteins (DAPs) between yak and cattleyak epididymis; 151 were up-regulated while 137 were down-regulated in cattleyak relative to yak. Gene Ontology analysis identified that down-regulated DAPs in cattleyak were mostly enriched in the acetylation of protein component, along with negative and positive regulatory activities. iTRAQ proteomics data showed that the top up-regulated DAPs were mainly enriched in cell communication, cell adhesion, cytoskeleton organization, stress response, post-translational modifications and metabolic functions while the down-regulated DAPs were predominantly associated with sperm maturation, long-term sperm storage, sperm forward motility, sperm-oocyte fusion and regulatory functions.
\end{abstract}

Conclusion: These results provide insight into the molecular mechanisms underlying male cattleyak sterility.

Keywords: Yak, Cattleyak, Epididymis, Sperm maturation, iTRAQ proteomics

\section{Background}

Cattleyak is the hybrid of cattle (Bos taurus) and yak (Bos grunniens) that demonstrates strong adaptability to harsh environmental conditions in the adjacent Alpine regions and the Qinghai-Tibetan Plateau in China [1]. Cattleyak provides higher quantity of meat and milk as compared to cattle and yak. The male cattleyak is sterile and this may be associated with spermatogenic arrest $[2$,

\footnotetext{
*Correspondence: zhujiang4656@hotmail.com; caixin2323@126.com ${ }^{3}$ Key Laboratory of Qinghai-Tibetan Plateau Animal Genetic Resource Reservation and Utilization (Southwest Minzu University), Ministry of Education, Chengdu 610041, Sichuan, China

Full list of author information is available at the end of the article
}

3] and/or some other factors such as genes or proteins expression dynamics along the epididymis. The sterility of male cattleyak phenomenon poses a major challenge and has restricted the hybridization procedure for decades. In previous years, not too many proteomics studies have been conducted to investigate male cattleyak sterility $[4,5]$. Most of the previous studies focused on testis and could not completely elucidate the exact cause of infertility in male cattleyak. Until now, no study has explored epididymis using iTRAQ proteomics as a means of identifying the sterility mechanism in male cattleyaks. Considering that testicular spermatozoa further

C C The Author(s). 2021 Open Access This article is licensed under a Creative Commons Attribution 4.0 International License, which permits use, sharing, adaptation, distribution and reproduction in any medium or format, as long as you give appropriate credit to the original author(s) and the source, provide a link to the Creative Commons licence, and indicate if changes were made. The images or other third party material in this article are included in the article's Creative Commons licence, unless indicated otherwise in a credit line to the material. If material is not included in the article's Creative Commons licence and your intended use is not permitted by statutory regulation or exceeds the permitted use, you will need to obtain permission directly from the copyright holder. To view a copy of this licence, visit http://creativecommons.org/licenses/by/4.0/ The Creative Commons Public Domain Dedication waiver (http://creativecommons.org/publicdomain/zero/1.0/) applies to the data made available in this article, unless otherwise stated in a credit line to the data. 
undergo mandatory epididymal maturation in the epididymis, it is therefore a suitable organ for further investigating male cattleyak sterility.

The epididymis is a long complex convoluted tube found on the surface of each testis, which connects the efferent duct to the vas deferens in the male mammalian reproductive tract [6]. The epididymal epithelium consists of 5 main epithelial cell types: principal, clear, basal, narrow, and halo cells; which provide not only structural support to epididymis but also play significant role in the epididymal spermatozoa maturation process [7]. The epididymis is the site where newly produced testicular spermatozoa acquire the ability to swim, penetrate and complete fertilizing competency. These functions are carried out from the secretion by epididymal epithelial cells (EECs) of several key proteins to create an interactive and dynamic microenvironment in the lumen where the spermatozoa are stored, protected, and undergo maturation. Moreover, Skerget et al. (2015) reported that, during sperm passage through the epididymis, the sperm surface protein must be acquired, lost, and modified to confer motility and fertilization competency to sperms [8]. With their significant functions in the process of sperm maturation and male fertility, the proteins have received considerable attention and have been assumed to be prospective targets for identifying and treating infertility. However, until now, very limited knowledge is available about the exact roles of proteins in the regulation of the several important processes involved in the epididymal sperm maturation and fertilization.

Advances in bioinformatics have greatly helped in understanding of sperm proteome composition and function. In recent years, some proteome studies have been successfully conducted in rat, human, and boar [9-11] by employing two-dimensional gel electrophoresis. However, the gel-based studies may suffer from drawbacks such as representation of the protein types at low concentrations and nature of the protein such as acidic or basic proteins [5]. Isobaric tagging for relative and absolute protein quantification (iTRAQ) is a proteomics technique developed to quantitatively investigate protein abundance changes in different biological samples with high accuracy and reproducibility and the advantage of this multiplexing reagent is that 4 or 8 analysis samples can be quantified simultaneously $[12,13]$. In this study, we identified proteins associated with sperm maturation between yak and cattleyak epididymis employing iTRAQ proteomics.

\section{Results}

Identification of differentially abundant proteins (DAPs) between yak and cattleyak epididymis by ITRAQ

We applied a quantitative iTRAQ-based proteomics approach for the determination of proteomic changes between yak and cattleyak epididymis. For the identification and relative quantification of proteins, an overview of workflow described by yak and cattleyak epididymis proteome comparison is shown in (Fig. 1). In 3 biological replicates, a total of 54,088 spectrums were generated and 4596 proteins were identified from 23,801 peptides between yak and cattleyak epididymis proteome. Normally, the number of proteins decreased from 1452 to 80 , as the increase in the protein coverage ranges from 0 to $100 \%$ (Fig. 2A). For the identification of peptide segments distribution, the Fig. $2 \mathrm{~B}$ shows that most of the identified proteins contain $<25$ peptide segments and the number of proteins segments decreased as the number of matching peptide segments was increased.

\section{Quantification of DAPs between yak and cattleyak epididymis by ITRAQ}

Out of the total identified proteins between yak and cattleyak epididymis proteome; 288 met the DAPs selection criteria, out of which 151 were up-regulated (fold change $\geq 1.5, p \leq 0.05)$ and 137 were $p \leq 0.05$ ). Down regulated DAPs including Vitamin D-binding protein, DnaJ homo$\log$ subfamily $C$ member 17 , and Serotransferrin had fold changes of $0.06,0.08$ and 0.10 respectively. On the other hand, 34 out of the 151 up-regulated proteins had fold change values $\geq 2$; among these were uncharacterized protein, A-kinase anchor protein 3, Uncharacterized protein, MHC class I antigen (Fragment), and Beta A4

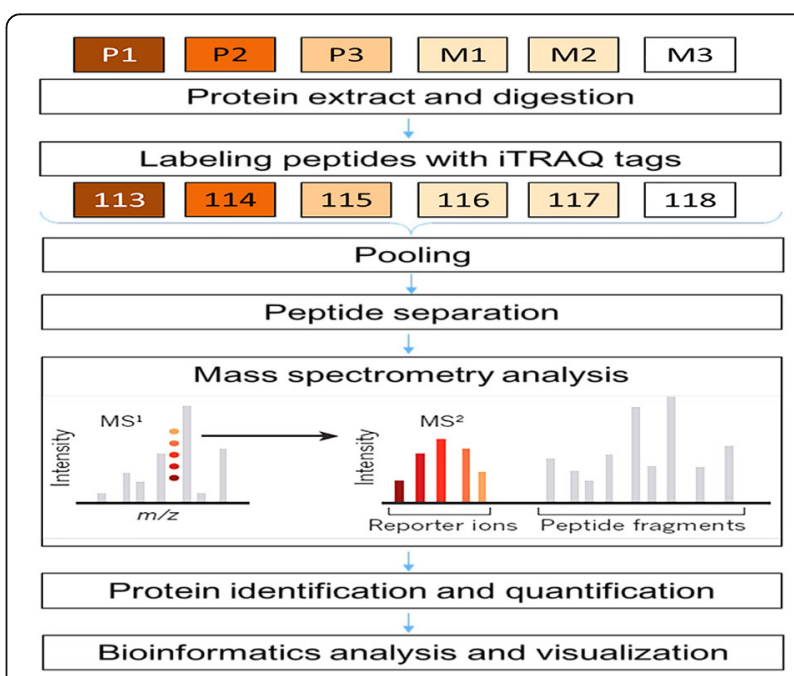

Fig. 1 The schedules of experimental treatment for the comparison of yak and cattleyak epididymal proteome. Proteins extracted from epididymis tissue samples were diminished, alkylated and enzymatically digested before labeling with iTRAQ, followed by LCMS/MS mass spectrometry analyses. In the last section, proteins were identified and quantified before analysing and visualization. Legends: Male cattleyaks ( $n=3$; age: 1 year; named P1, P2, and P3) and Male yaks ( $n=3$; age: 1 year; named M1, M2, and M3)" 


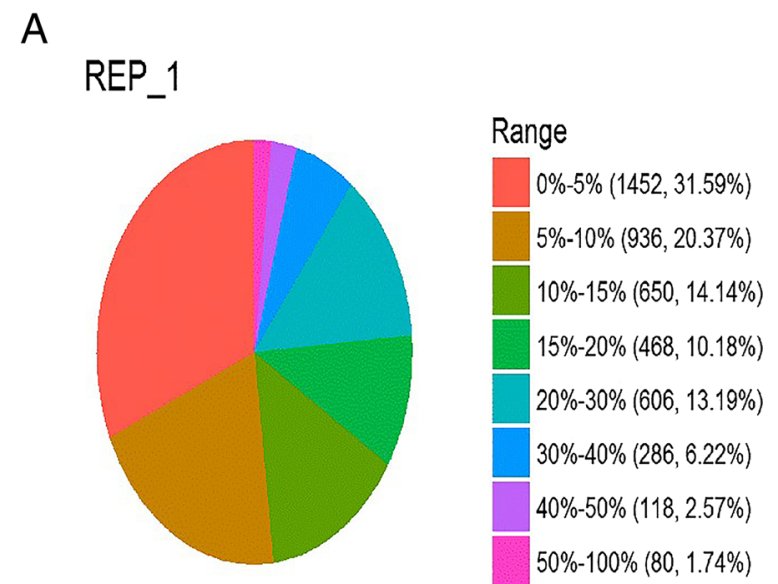

B

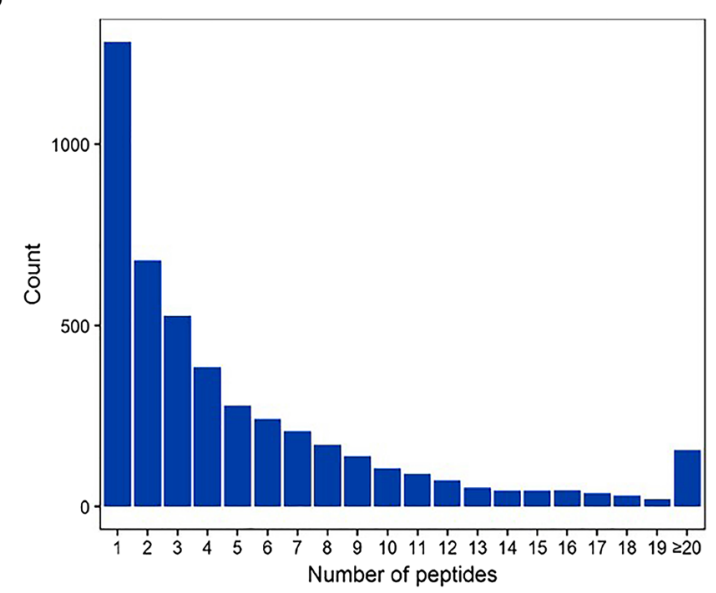

Fig. 2 Peptide sequence coverage and identification of number of peptides. The $\mathbf{A}$ shows the proportion of proteins in different coverage ranges. The different colors representing different ranges of sequence coverage. The brackets show the number of proteins in different coverage ranges and their proportion to the total protein. The $\mathbf{B}$ shows the distribution of the number of peptides contained in the identified protein. The $x$-axis is the range of peptides covering the protein, and the $y$-axis is the number of proteins

crystallin with fold changes of 4.6, 4.2, 3.9, 3.8, and 3.8 respectively. We have listed top 30 up-regulated DAPs and top 30 down-regulated DAPs identified from cattleyak relative to yak (Tables 1 and 2, respectively).

\section{Gene ontology (GO) analysis of the differentially abundant proteins}

Gene ontology (GO) analysis was conducted to better understand the functions of the all down-regulated and up-regulated DAPs identified by iTRAQ between yak and cattleyak based on biological process, cellular component, and molecular function categories. $35 \mathrm{GO}$ terms were significantly enriched for down-regulated DAPs, including 22 biological process terms, 6 cellular component terms, and 7 molecular function terms. Majority of these down-regulated enriched GO terms relating to biological processes were mainly associated with acetylation of protein components, negative regulatory activity, and positive regulatory activity, from which top three listed enriched GO terms were negative regulation of endopeptidase activity $(p=0.002923)$, negative regulation of peptidase activity $(p=0.003519)$ and histone $\mathrm{H} 3$ acetylation $(p=0.005172)$. According to the downregulated cellular components, most of enriched GO terms were associated with acetyltransferase complex, among which the top three listed enriched GO terms include histone acetyltransferase complex $(p=0.002818)$, acetyltransferase complex $(p=0.004352)$ and protein acetyltransferase complex $(p=0.004352)$. From downregulated molecular functions, majority of enriched GO terms were involved in inhibitor activity and regulator activity, among which top three listed enriched GO terms include peptidase regulator activity $(p=0.011867)$, antigen binding $(p=0.020786)$, and endopeptidase inhibitor activity $(p=0.021568)$ (Fig. 3A), while, among the up-regulated DAPs, 48 GO terms were significantly enriched between yak and cattleyak epididymis, including 18 biological process terms, 7 cellular component terms, and 23 molecular function terms. Most of the upregulated DAPs enriched GO terms in particular to biological processes were involved in metabolic processes, protein localization and catabolic processes, among which top three listed enriched GO terms include organonitrogen compound catabolic process $(p=0.004521)$, receptor-mediated endocytosis $(p=0.005261)$ and cellular modified amino acid metabolic process $(p=$ 0.006143). With respect to cellular component, the most important up-regulated enriched GO terms were lysosome and sperm part, in which top three listed enriched GO terms were lysosome $(p=0.001189)$, lytic vacuole $(p=0.001189)$ and blood microparticle $(p=0.005987)$. Significantly up-regulated enriched GO terms based on molecular function were associated with binding, inhibitor activity, and hydrolase activity, in which top three enriched GO terms were hydrolase activity ( $p=1.26 \mathrm{E}$ $05)$, vitamin $\mathrm{D}$ binding ( $p=0.000388)$ and steroid binding $(p=0.001698)$ (Fig. 3B).

\section{KEGG pathway enrichment analysis of DAPs}

Pathway analysis for identified proteins can deepen our understanding of the metabolic capacity of the species, biological processes information, and related diseases. In this study, we have mapped 87 down-regulated DAPs and 136 up-regulated DAPs to the reference pathways in the KEGG database to determine biological pathways related to sperm function. In total, five up-regulated DAPs were significantly enriched in KEGG pathways whereas none of the down-regulated DAPs were significantly enriched in KEGG pathways. For the up-regulated DAPs, 
Table 1 The top 30 down-regulated differentially abundant proteins (DAPs) between yak and cattleyak epididymis

\begin{tabular}{|c|c|c|c|c|}
\hline Accession & Description of Protein & Protein symbol & $P$ value & $\mathrm{FC}(\mathrm{P} / \mathrm{M})$ \\
\hline F1N5M2 & Vitamin D-binding protein & GC & 4.65E-09 & 0.062 \\
\hline Q2KI83 & DnaJ homolog subfamily C member 17 & DNAJC17 & 0.000100554 & 0.081 \\
\hline G3X6N3 & Serotransferrin & TF & 0.006778114 & 0.106 \\
\hline A0JNP2 & Secretoglobin family 1D member (LppAB) & SCGB1D & 0.001735233 & 0.181 \\
\hline D4QBB3 & Hemoglobin beta & $\mathrm{HBB}$ & $1.06 \mathrm{E}-05$ & 0.225 \\
\hline E1B9W6 & Uncharacterized protein & $A D C Y 10$ & 0.000214338 & 0.241 \\
\hline A7Z033 & T-complex protein 11-like protein 2 & TCP11L2 & 0.007235083 & 0.256 \\
\hline P33433 & Histidine-rich glycoprotein (Histidine-proline-rich glycoprotein) (HPRG) (Fragments) & HRG & 7.60E-07 & 0.272 \\
\hline A5D7S6 & PEF1 protein & PEF1 & 0.001584413 & 0.286 \\
\hline Q3MHV8 & RBM15B protein (Fragment) & RBM15B & 0.000115054 & 0.294 \\
\hline B0JYP6 & IGK protein & IGK & 0.002491825 & 0.295 \\
\hline G3N1U4 & Serpin A3-3 & SERPINA3-3 & 4.24E-07 & 0.306 \\
\hline Q9XSK2 & CD63 antigen (CD antigen CD63) & CD63 & 7.98E-09 & 0.316 \\
\hline QOIIG7 & Ras-related protein Rab-5A & RAB5A & 0.000214338 & 0.318 \\
\hline F6RF62 & Uncharacterized protein & MYL4 & $1.97 \mathrm{E}-08$ & 0.344 \\
\hline G9HQZ5 & MHC class I antigen (Fragment) & BoLA & 0.000559995 & 0.362 \\
\hline E1BND7 & Uncharacterized protein & PPFIA2 & 0.007269613 & 0.373 \\
\hline Q58D67 & Dynactin 4 & DCTN4 & $2.36 \mathrm{E}-05$ & 0.403 \\
\hline Q3SZK1 & Angio-associated migratory cell protein & AAMP & 0.004313819 & 0.409 \\
\hline $\mathrm{E} 1 \mathrm{BPI} 2$ & Non-specific serine/threonine protein kinase (EC 2.7.11.1) & & 0.006717303 & 0.412 \\
\hline Q3ZCH5 & Zinc-alpha-2-glycoprotein (Zn-alpha-2-GP) (Zn-alpha-2-glycoprotein) & AZGP1 & 0.007264748 & 0.426 \\
\hline A6QQR0 & WDR75 protein & WDR75 & $2.56 \mathrm{E}-05$ & 0.427 \\
\hline Q2KJ61 & Elongator complex protein 3 (EC 2.3.1.48) & ELP3 & 0.000855102 & 0.435 \\
\hline E1BIM7 & Uncharacterized protein & CELF2 & 0.005137574 & 0.439 \\
\hline E1BGN3 & Histone H3 & $\mathrm{HIST} 2 \mathrm{H} 3 \mathrm{D}$ & $2.16 \mathrm{E}-15$ & 0.444 \\
\hline $\mathrm{A} 1 \mathrm{~A} 4 \mathrm{~J} 3$ & Zinc finger, $\mathrm{CCHC}$ domain containing 3 & $\mathrm{ZCCHC3}$ & 0.000169658 & 0.449 \\
\hline E1BE33 & Uncharacterized protein & ZEB2 & $1.58 \mathrm{E}-09$ & 0.450 \\
\hline G3MZD8 & Uncharacterized protein & & 0.002250709 & 0.452 \\
\hline E1BEP7 & Uncharacterized protein & ELP2 & 0.00728467 & 0.459 \\
\hline Q08E58 & Tubulin tyrosine ligase-like family, member 12 & TTLL12 & 0.000147691 & 0.467 \\
\hline
\end{tabular}

the enriched KEGG pathways were associated with Glutathione metabolism ( $p=9.75 \mathrm{E}-05)$, Lysosome ( $p=$ $0.000102)$, Glycan degradation $(p=0.000646)$, Glycosaminoglycan degradation $(p=0.01678)$ and Thyroid hormone synthesis $(p=0.021941)$ (Fig. 4).

\section{Protein-protein interaction (PPI) of DAPs}

In this study, the Search Tool for the Retrieval of Interacting Genes /Proteins 11.0 (STRING 11.0) database was used for identifying protein-protein interaction network of DAPs. After removing unconnected and self-loops proteins, the resulting PPI network generated 64 protein nodes and 90 edges (in Fig. 5). Furthermore, the network data file was directly imported into Cytoscape software for visual editing with a threshold value of a combined score $>0.7$. DAPs that connected higher than others in created network were considered as hub proteins (Fig. 6); these hub proteins may have significant roles in the regulation of the network. In the PPI network, the top four hub proteins include vesicleassociated membrane protein 8 (VAMP8), SERPINA3-3, GGH, and DNAJC3.

\section{Elisa}

ELISA was performed to verify the results obtained from iTRAQ proteomics. The up-regulation of GGH, RAP1, GPX5 and MUC15 in cattleyak with respect to yak determined by iTRAQ was confirmed by ELISA $(p<0.05)$. Meanwhile, ELISA also verified the decreased expression of CD63, ELP3, LSM5 and GSTM1 in cattleyak compared to yak as identified by iTRAQ $(p<0.05)$ (Fig. 7). All these data validated the results obtained from iTRAQ.

\section{Discussion}

Proteomics technologies present major possibilities to investigate the molecular mechanisms that regulate the 
Table 2 The top 30 up- regulated differentially abundant proteins (DAPs) between yak and cattleyak epididymis

\begin{tabular}{|c|c|c|c|c|}
\hline Accession & Description of Protein & $\begin{array}{l}\text { Protein } \\
\text { symbol }\end{array}$ & $P$ value & $\begin{array}{l}\mathrm{FC}(\mathrm{P} / \\
\mathrm{M})\end{array}$ \\
\hline $\mathrm{E} 1 \mathrm{BKY} 2$ & Uncharacterized protein & & 0.00881948 & 4.65 \\
\hline F1MJS8 & A-kinase anchor protein 3 & AKAP3 & 0.000526461 & 4.26 \\
\hline F1MIM1 & Uncharacterized protein & LOC104976250 & 0.000889658 & 3.89 \\
\hline Q3YJL1 & MHC class I antigen (Fragment) & BoLA & 0.007469039 & 3.81 \\
\hline Q6DTZ8 & Beta A4 crystallin (Beta-crystallin A4) & CRYBA4 & 8.45E-09 & 3.80 \\
\hline G3N2N9 & Glutathione peroxidase & GPX5 & $7.28 \mathrm{E}-05$ & 3.55 \\
\hline E1BE11 & Uncharacterized protein & HMCN1 & $5.28 \mathrm{E}-09$ & 3.53 \\
\hline F1MIM0 & Uncharacterized protein & & 0.000618683 & 3.41 \\
\hline Q32KP8 & Serine peptidase inhibitor-like, with Kunitz and WAP domains 1 (Eppin) & SPINLW1 & 1.30E-19 & 3.34 \\
\hline Q0VCG3 & Parvalbumin alpha & PVALB & 0.000112643 & 3.03 \\
\hline E1BGB7 & Uncharacterized protein & & 1.07E-05 & 2.85 \\
\hline Q3MHJ9 & $\begin{array}{l}\text { Calcium/calmodulin-dependent protein kinase type II subunit beta (CaM kinase II subunit beta) } \\
\text { (CaMK-II subunit beta) }\end{array}$ & CAMK2B & 0.001572046 & 2.79 \\
\hline Q70|B2 & Inactive ribonuclease-like protein 10 (Protein Train A) & RNASE10 & 0.000205134 & 2.77 \\
\hline F1MY32 & Uncharacterized protein & LY6G5C & 0.004856315 & 2.76 \\
\hline F1MSZ5 & Uncharacterized protein & ADAM28 & 1.08E-09 & 2.72 \\
\hline P02192 & Myoglobin & $\mathrm{MB}$ & $3.62 \mathrm{E}-05$ & 2.65 \\
\hline $\mathrm{A} 6 \mathrm{H} 742$ & Plastin-1 & PLS1 & 7.90E-07 & 2.64 \\
\hline G3N2L2 & Uncharacterized protein & RCN1 & 0.000161915 & 2.58 \\
\hline F1MTV5 & Amino acid transporter & SLC1A5 & 0.004519988 & 2.56 \\
\hline F1N5W4 & Uncharacterized protein & ENPP5 & 0.000276382 & 2.52 \\
\hline F1N2E1 & Uncharacterized protein & WFDC8 & 0.0076419 & 2.45 \\
\hline Q2TBR5 & Protein FAM166B & FAM166B & $2.10 \mathrm{E}-08$ & 2.42 \\
\hline Q0VCU3 & Cathepsin F & CTSF & 0.002189062 & 2.33 \\
\hline A7E340 & Mucin 15, cell surface associated & MUC15 & 7.89E-33 & 2.32 \\
\hline E1BD73 & Poly [ADP-ribose] polymerase (PARP) (EC 2.4.2.30) & PARP4 & $5.16 \mathrm{E}-14$ & 2.31 \\
\hline F1MG20 & 17-beta-hydroxysteroid dehydrogenase type 6 & HSD17B6 & 0.002590687 & 2.26 \\
\hline F1MV86 & G1/S-specific cyclin-D3 & CCND3 & 0.000102853 & 2.25 \\
\hline A6QQ08 & SNCA protein (Fragment) & SNCA & 0.009021835 & 2.24 \\
\hline F1MUC1 & Uncharacterized protein & $\mathrm{ABCC} 4$ & 4.25E-06 & 2.21 \\
\hline E1BJ49 & Uncharacterized protein & MASP2 & 0.000448626 & 2.18 \\
\hline
\end{tabular}

functional activities of the sperm [14]. Initially, the iTRAQ proteomics technique was used to study male cattleyak infertility with an increased focus on the testis. Until now, no research has used the aforementioned methodology to analyze the epididymis, which is recognized to be morphologically and functionally active in sperm maturation and fertility. In this study, iTRAQ proteomics is employed in the analysis of proteins associated with sperm maturation in the epididymis of yak and cattleyak. The epididymis serves important functions, including post-testicular sperm maturation which is important as it provides suitable environment for spermatozoa to develop progressive movement capacity and fertilization competence. The dynamic nature of the epididymal environment ensures that problems in the signaling pathways lead to infertility. In the epididymis the sperm protein, lipid and small RNA content are highly modified as a result of the continuous interaction with luminal proteins mainly secreted by the epididymal epithelium and extracellular vesicles, epididymosome [15]. Epididymal maturation happens as structural modifications in the epididymis occur, allowing sperm to capacitate in the female reproductive tract [16]. This study focuses on epididymal proteins and shows how they affect sperm functions. However, there exist major group of proteins identified to be expressed in testis as well as epididymis and they play specific important roles in sperm functions. 

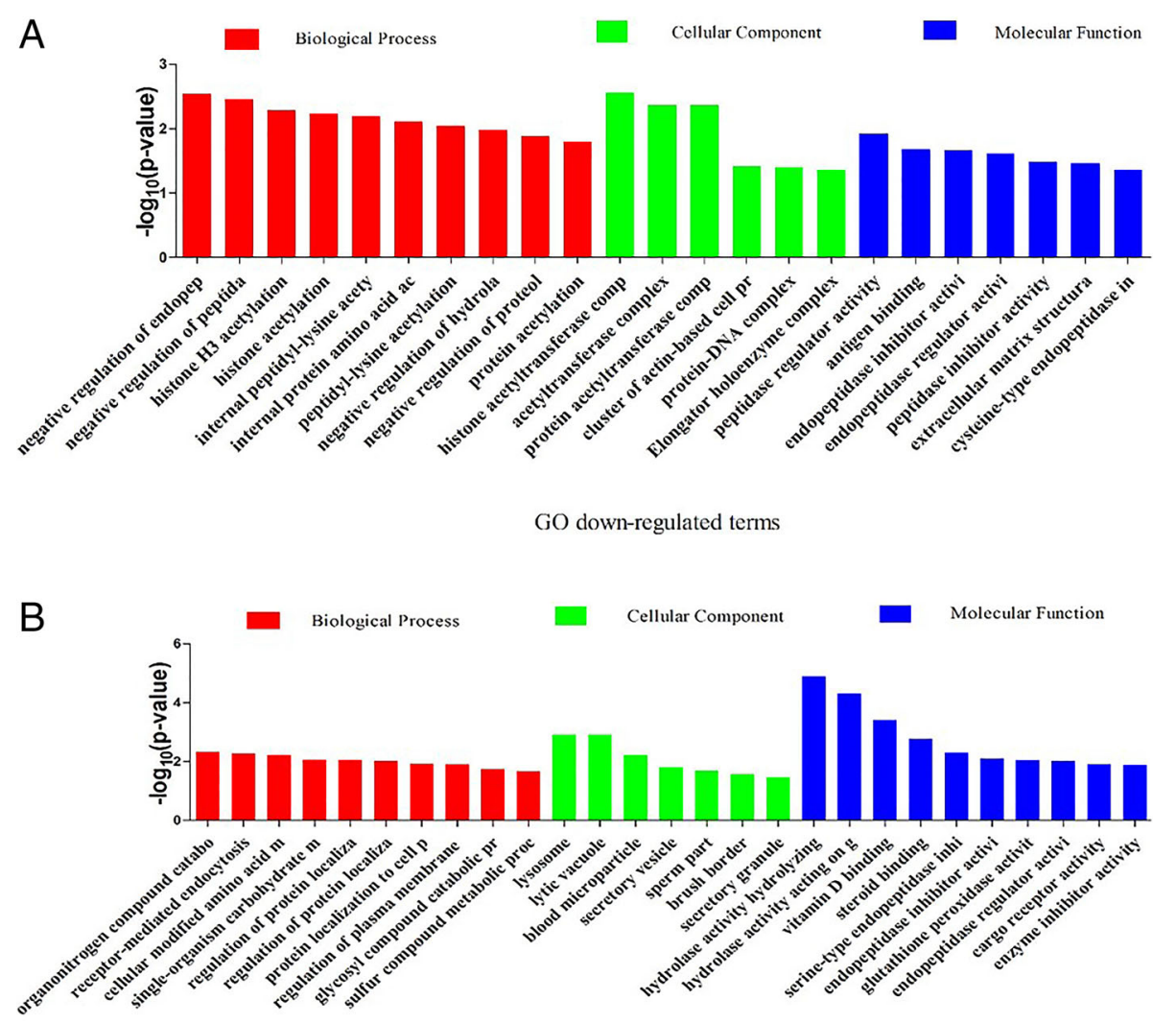

GO up-regulated terms

Fig. $3 \mathrm{GO}$ classification of DAPs in cattleyak compared to yak. The $\mathbf{A}$ describes GO terms of down-regulated DAPs and the $\mathbf{B}$ describes the GO terms of up-regulated DAPs. The x-axis represents the number of GO terms and y-axis represents $p$-value of each GO terms

\section{Epididymal sperm maturation}

The functional analysis identified a number of downregulated DAPs involved in epididymal maturation in cattleyak (Table 1). Phosphatidylethanolamine-binding protein 4 (PEBP4) was studied in fertile, low fertile, and infertile bulls and found that the novel seminal PEBP4 expression was significantly higher in fertile bulls relative to low fertile and infertile bulls, implying that PEBP4 could play important roles in spermiogenesis, epididymal

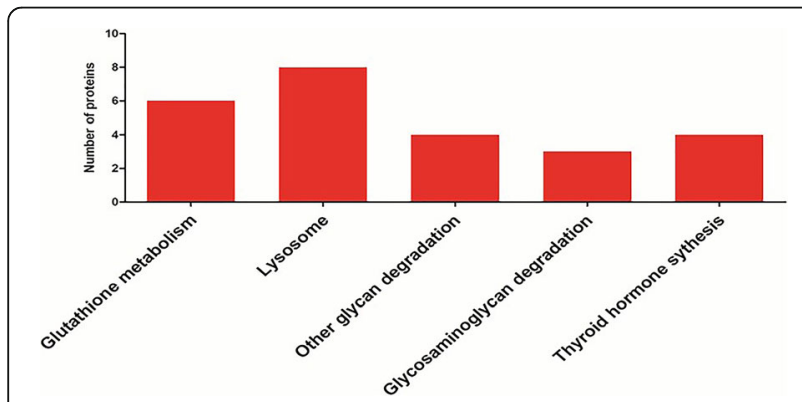

Fig. 4 KEGG pathway enrichments analysis of DAPs in cattleyak with respect to yak. The $x$-axis displays each of the enriched pathways. The $y$-axis shows the number of DAPs in each pathway sperm maturation, and sperm motility [17]. The existing evidence suggests that, down-regulation of PEBP4 in cattleyak could compromise sperm maturation processes and result in infertility. CD63, is a recognized exosome marker that is found in the apices of epididymal epithelial principal cells and the epididymal microenvironment, allowing for long-term sperm storage [18]. The protein facilitates signal transduction functions, which are important in regulating cellular proliferation, growth, and motility. Downregulation of CD63 in cattleyak could have a significant impact on sperm storage and lead to fertility problems. Seminal plasma contains proteins associated with sperm progressive motility, including Zincalpha-2-glycoprotein (ZAG) and could play functional roles during maturation of spermatozoa, from the epididymis through fertilization in the female reproductive tract [19]. The downregulation of ZAG in cattleyak suggests that sperms may well not develop progressive motility after ejaculation through into female reproductive tract.

Glutathione S-transferase $\mathrm{Mu} 1$ (GSTM1-1) and Fetuin-B were also found to be down-regulated in cattleyak compared to yak. The possible role of Glutathione 


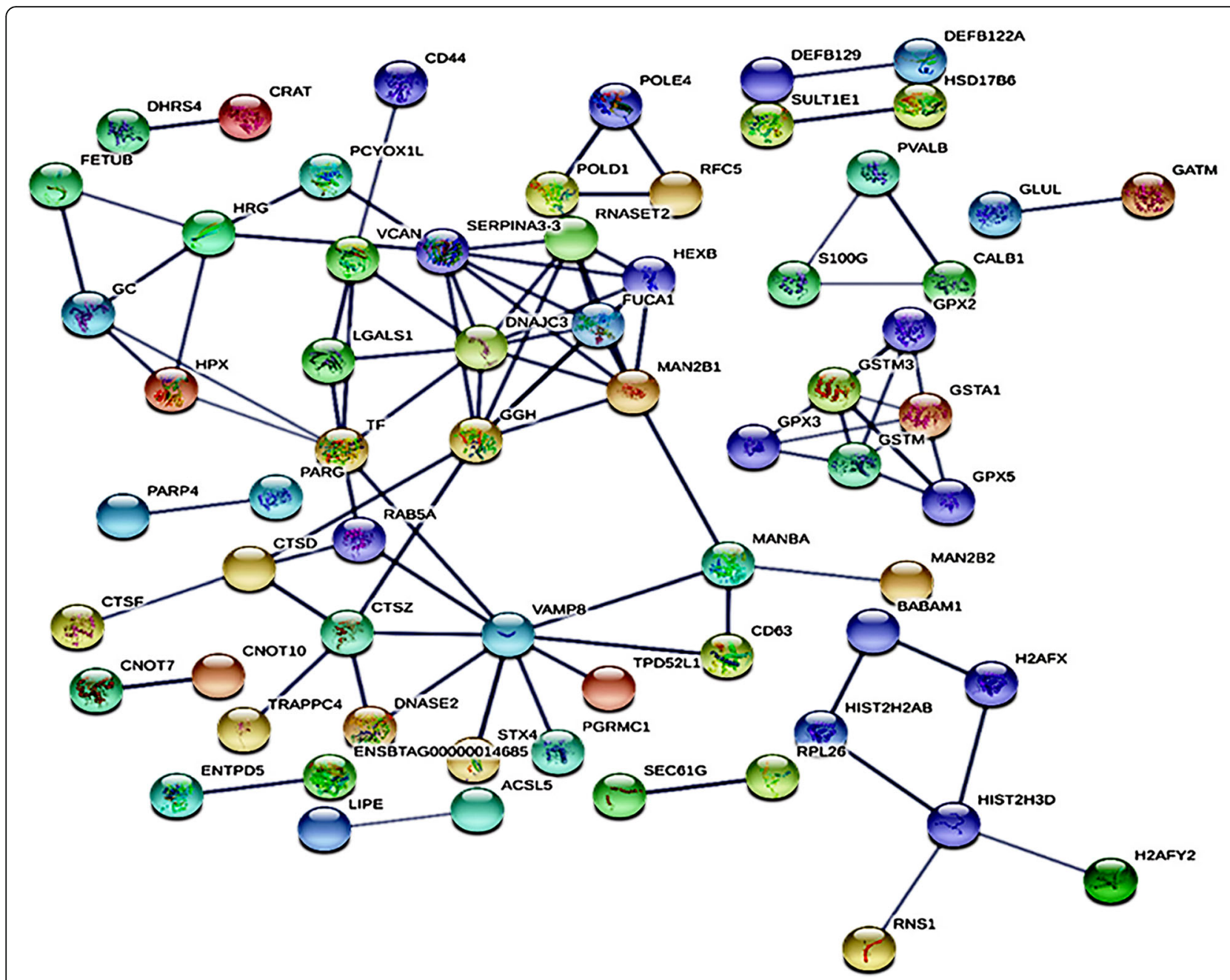

Fig. 5 Protein-protein interaction (PPI) network of DAPs in cattleyak created by STRING database

S-transferase Mu 1 (GSTM1-1) in the epididymis is unspecified, despite the fact that it is a member of the Glutathione S-transferase mu class (GSTM1) found on sperms. GSTM1 is known to be associated with spermoocyte fusion and promotes precise joining of sperm surface-active components with the zona pellucida (ZP) during the sperm-egg fusion process [20,21]. Decreased GSTM1-1 expression could be a potential cause of reduced or impaired fertilization in cattleyak. Fetuin-B was identified in mice as a plasma protein inhibiting ovastacin, a cortical granula protease known to cause ZP hardening and infertility [22, 23]. It is possible that downregulation of Fetuin-B in cattleyak resulted in similar effects. The biological roles of the aforementioned proteins indicate that their downregulation could have a detrimental impact on sperm maturation, long-term sperm storage, sperm forward motility, and spermoocyte interaction.

\section{Epididymal dysfunction}

In general, the epididymis comprises a variety of molecules and proteins that aid sperms in their quest to fertilize oocytes. Nuclear pores, which are essential in the exchange of macromolecules such as proteins and RNAs, facilitate interaction between the nucleus and the cytoplasm in eukaryotic cells. The nuclear localization signal (NLS), which is made up of 100 different proteins, particularly Importin subunit alpha, mediates active nuclear protein transport by recognizing karyophile proteins and forming a stable complex known as the nuclear pore-targeting complex (PTAC) [24, 25]. Importin subunit alpha's biological activity indicates that increased expression of this protein may block the critical contact between nucleus and cytoplasm in cattleyak epididymal cells, causing infertility. Mucins form highly glycosylated proteins which are classified into two types: secretory mucins and membrane-bound mucins. Mucin 


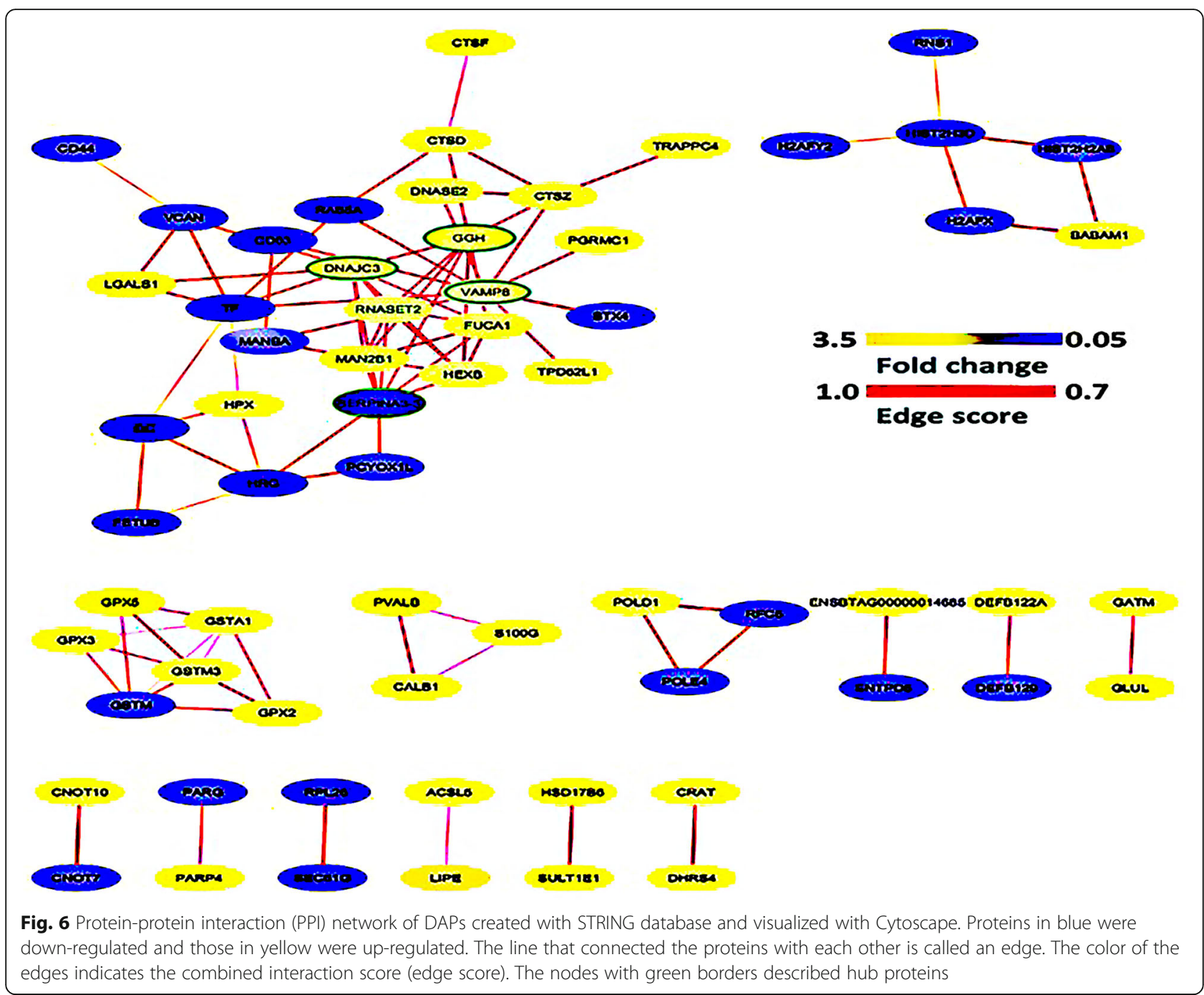

15 have been discovered to be a membrane-bound mucin expressed by epithelial cells, implying that changes in membrane-bound mucins could affect cellular development, differentiation, transformation, invasion, and adhesion [26]. Mucin 15 upregulation in cattleyak suggests that Mucin 15 could perhaps enhance adhesion, which may affect or interfere with sperm cell migration through the epididymis. GAS2 was discovered to be a part of the microfilament system, associated with cell growth arrest through a phosphorylation mechanism during the Go-G1 transition [27]. GAS2 overexpression causes membrane ruffling and the termination of mitosis [28]. The upregulation of GAS2 in cattleyak could have affected the vital molecules or cells participating in the overall growth of sperms in the cattleyak epididymis.

Aminopeptidase and Poly (ADP-ribose) polymerase (PARP) were also found to be up-regulated in cattleyak and are known to be involved in a variety of stress responses. Aminopeptidase, an enzyme encoded by the
Endoplasmic reticulum aminopeptidase 1 (ERAP1) gene, was thus discovered to play a key role in immune response [29]. Aminopeptidase perform functions similar to acute-phase proteins thus, it is secreted into the blood in response to inflammatory stimuli and is involved in increasing nitric oxide (NO) synthesis as a host defense mechanism [30]. Poly (ADP-ribose) polymerase (PARP) functions as a DNA repair enzyme present in a variety of tissues, including the epididymis and it is activated when a DNA strand splits as a result of reactive oxygen species (ROS) or oxidative stress [31, 32]. PARP is activated by nicotinamide-adenosine dinucleotide (NAD) which results in ADP-ribosylation of PARP. Excessive PARP activation has been attributed to NAD+ depletion and corresponding cellular ATP depletion, eventually leading to necrotic-type cell death [33]. This could be explained that increased Aminopeptidase and PARP expression levels led to an increase in a constant stress state of sperm cells involving the acquisition of certain toxic 


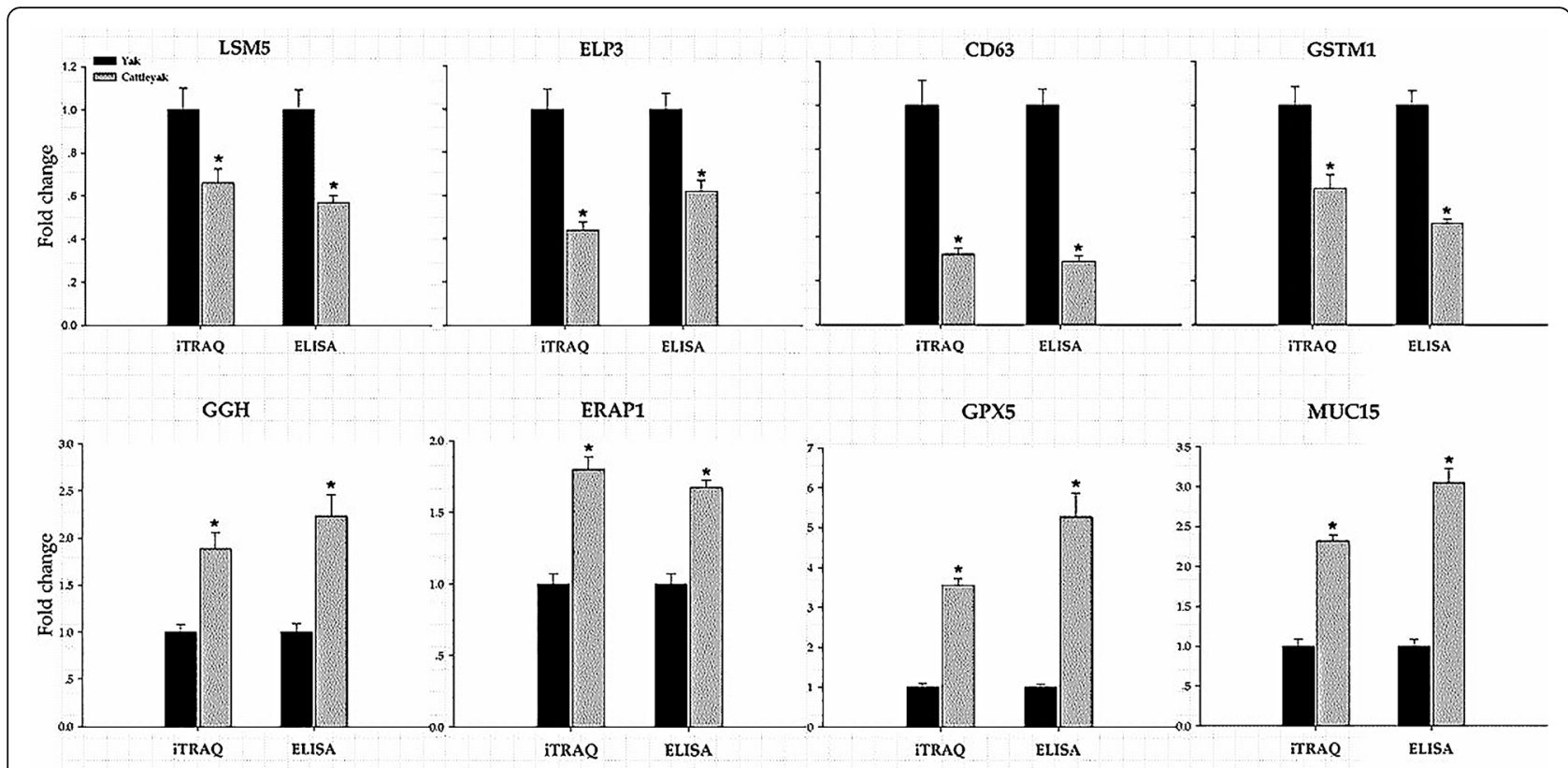

Fig. 7 Validation of iTRAQ data with ELISA. The vertical axis indicates the fold change of protein abundance. The horizontal axis indicates the methods for ELISA and iTRAQ. In each method, the protein expression level of yak was the control and designated as 1 to determine the expression level of cattleyak. Expression level of each protein is the mean of three replicates for cattleyak and plotted (mean \pm SD) in relation to yak as control $(Y=1)$. The expression pattern of the protein CD63, ELP3, LSM5, GSTM1, GGH, ERAP1, GPX5 and MUC15 was validated respectively. *Protein expression were significantly different from control ( $p<0.05$, Student's t-test)

substances formed by altered DAPs. Moreover, mammalian epididymal spermatozoa achieve fertility development by a mechanism known as post-translational modifications [34]. Polypeptide N-acetylgalactosaminyltransferase 6 (GalNAc-T6) is a member of the polypeptide Nacetylgalactosaminyltransferase (GalNAc-Ts) family that take active part in catalyzing the transport of N-acetylD-galactosamine: polypeptide (GalNAc) from the sugar donor uridine diphosphate (UDP)-GalNAc to the serine and threonine residues of glycoproteins [35]. Previous research has shown that the modulation of spermatozoa plasma glycoproteins is essential for the development of functionally mature sperms during migration through the epididymis [36, 37]. As a result, up-regulation of GalNAc-T6 could modulate glycosylation and have a significant negative effect on sperm motility and perhaps on the fertility process.

Proteolytic cleavages of surface proteins by protease enzymes are essential for the interactions of spermatozoa and zona pellucida. Protease inhibitors regulating the sperm membranes prevent premature capacitation, thereby controlling the proteolytic cascades [38]. Serpin A3-8 was discovered in buffalos as a protease inhibitor and served active in the protease inhibition mechanism [39]. An essential Serine peptidase inhibitor-like protein $(\mathrm{M} / P=3.339198)$ with Kunitz and WAP domains 1 (Eppin) were discovered in male monkeys and the high-titer monkeys were found to be infertile [40]. As a result of the increased expression of these protease inhibitors, they could inhibit proteolytic cleavages needed for the early events of fertilization. Consequently, the biological functions of the proteins were associated with cell communication, cell adhesion, cytoskeleton organization, stresses, and post-translational modifications.

\section{Regulatory mechanisms}

Different luminal environments exist within the epididymis, an undifferentiated epithelium undergo various sequence of modifications to become completely differentiated, with differences in anatomy, gene regulating activities, and functions [41]. The mechanisms involved in gene expression are regulated at many different levels, from transcription to protein posttranslational modifications. These highly complex processes necessitate the involvement of a variety of key proteins that are responsible for the activation of critical pathways. GO biological function analyses revealed a number of down-regulated DAPs involved in regulation and acetylation. The central objective of control in gene expression mechanisms is the transcriptional level, where histones and their acetylation in nucleosomes play functional roles in regulating gene expression. Histone $\mathrm{H} 2 \mathrm{~A}$ and its variant Core histone macro-H2A were identified as members of histone octamer that formed a structural unit (nucleosome) of chromatin $[42,43]$. Histone $\mathrm{H} 2 \mathrm{~A}$ possesses $\mathrm{N}$-terminal tail (H2ANtT) and Cterminal tail ( $\mathrm{H} 2 \mathrm{ACtT})$. The H2ANtT perform essential functions mainly in inter-nucleosome interaction [44], 
while $\mathrm{H} 2 \mathrm{ACtT}$ recruits linker histone $\mathrm{H} 1$ to the nucleosome and stabilizes it [45]. Deletion of H2ACtT could increase $\mathrm{H} 2 \mathrm{~A}$ mobility and also decrease nucleosome stability. Elongator complex protein 3 (ELP3) was found as a catalytic subunit of Elongator protein encoding a histone acetyltransferase and facilitating histone acetylation [46]. Acetylation of histones permits chromatin to reveal DNA binding sites and initiate transcription [47]. As a result, it is possible that the down-regulation of Histone H2A and ELP3 in cattleyak is a source of transcriptionally silenced genes that encode essential epididymal sperm maturational proteins.

Post-transcriptional regulation of genes could be controlled by the processes of deadenylation and pre-mRNA splicing. CCR4-NOT transcription complex subunit 7 or CCR4-associated factor 1 (CAF-1) serves as a deadenylase enzyme in the mRNA degradation process, during which poly (A) tail is eliminated and the newly synthesized mRNA is highly decreased from 200 to 250 nucleotides to 10-60 nucleotides [48, 49]. The poly (A) tail length is considered important in mRNA stability, translation efficiency, and gene regulation [50], whereas U6 snRNA-associated $\mathrm{Sm}$-like protein $\mathrm{LSm} 5$ serves as a major component of spliceosome initiating significant functions in pre-mRNA splicing mechanisms, resulting in the development of maturated mRNA [51]. Multiple protein isoforms could be derived from a single gene during the pre-mRNA splicing process, and they could play an important role in cellular differentiation and organism growth [52]. Down-regulation of U6 snRNAassociated Sm-like protein LSm5 could facilitate the disruption of normal cellular functions, resulting in infertility. Furthermore, Aspartyl-tRNA synthetase (AspRS) and Protein transport protein Sec61 subunit gamma were discovered to be active in translational and posttranslational processes, respectively. Aminoacylation is the mechanism by which tRNAs are charged prior to initiating the translation process. AspRS is an aminoacyltRNA synthetase which charges its cognate tRNA with aspartate amino acid and is involved in the oxidative stress response [53]. However, transport protein Sec61 subunit gamma which is a component of proteinconducting channel (PCC) resides in the membrane of the endoplasmic reticulum, where it binds to translating ribosomes for co-translational protein transport [54]. The biological functions of the translational and posttranslational proteins revealed that their downregulation may result in the inability of proteins to fold efficiently in the endoplasmic reticulum (ER).

\section{Metabolic functions}

Metabolism involves series of chemical and physical modifications that develop in the body of animals, providing energy for the synthesis of newly required life processes. GO biological function analysis revealed a number of up-regulated DAPs involved in certain metabolism processes in cattleyak. It was previously reported that targeting sperm and energy metabolism have a stronger relationship [55]. We recognized specific significant candidates for up-regulated DAPs involved in metabolic functions in this study: Biliverdin reductase A (BVR A) and Gamma-glutamyl hydrolase (GGH). In mammalian epididymis, Biliverdin (BV) and its reduced form, bilirubin (BR), perform essential functions. BVRA was identified as an enzyme that converted biliverdin to bilirubin and therefore considered to play a crucial role in scavenging reactive oxygen species (ROS), reactive nitrogen species (RNS), and nitric oxide through its substrate (BV), which is also a by-product (BR) [56, 57]. The increased expression of BVRA in the epididymis of cattleyaks could restrict the capacity and quantity of biliverdin to facilitate certain oxidant activities. Proteins, micro and macronutrients all play important roles in fertilization; folate is a micronutrient that remains essential for sperm quality. Sperm aneuploidy has a negative impact on sperm production and could be reduced by consuming $400 \mathrm{mg}$ to $700 \mathrm{mg}$ total folate per day [58]. Gamma-glutamyl hydrolase (GGH) was discovered to be a lysosomal enzyme active in dietary folylpoly-yglutamate metabolism, allowing folylmonoglutamate to reach the intestinal membrane to play a significant functions in folate cellular homeostasis [59]. The biological function of GGH suggests that overexpression of this protein could compromise cellular folate maintenance and have a negative impact on cattleyak sperm production.

\section{Conclusion}

We identified a total of 4596 proteins between yak and cattleyak epididymis. Out of the total, 288 were DAPs, of which 151 were up-regulated DAPs and 137 were downregulated DAPs. Most of the identified proteins in cattleyak were involved in epididymal sperm maturation, epididymal dysfunction, regulatory and metabolic functions. iTRAQ proteomics data identified several key DAPs (PEBP4, CD63, ZAG, GSTM1-1, and Fetuin-B) that potentially play significant roles in the sperm maturation process in cattleyak. These results provide insight into the molecular mechanisms underlying male cattleyak sterility as upregulation and downregulation of certain important DAPs in the epididymis impede the normal development of a fertile ejaculate and represent a part of the causes of infertility. Continuously understanding the specific functional descriptions of the key DAPs may facilitate proper breeding techniques. Numerous DAPs from this study may be useful for further studies on the molecular mechanisms causing male cattleyak sterility. 


\section{Methods}

\section{Animals and epididymis sample collection}

Samples were collected under license in compliance with the Chinese Guidelines for the Care and Use of Laboratory Animals, and all procedures were authorized by the Southwest University of Science and Technology's Institutional Review Board [60]. Male yaks (Maiwa yaks) ( $n=3$; age: 1 year; named M1, M2, and M3) and Male cattleyaks (Maiwa yak $\times$ Tibetan taurine) $(n=3$; age: 1 year; named P1, P2, and P3) were sampled from Maiwa yak population fed on a farm in Hongyuan county, Sichuan province of China.

Veterinary surgery was used to extract epididymides from yaks and cattleyaks, fat and connective tissues were removed. Epididymides were separated apart from testis by fine-scale dissection and preserved in liquid nitrogen $\left(-196^{\circ} \mathrm{C}\right)$, transported to the laboratory and stored at $-80^{\circ} \mathrm{C}$ until further analysis. After the samples were collected, the animals were treated and stored in a safe and enclosed area near to the farm-house.

\section{Total protein extraction from epididymal tissue}

Total protein was extracted from the epididymal tissue that contained sperm. Cryogenic grinding with mortar and pestle of each epididymal tissue sample was performed and for protein stability, lysis buffer (7 M urea, 2 $\mathrm{M}$ thiourea, $0.1 \%$ CHAPS) was added and vortexed to mix. Ultrasonic extraction of lysates, centrifugation and storage followed [61]. The spectroscopic Bradford protein assay was used to measure the concentration of the extracted protein. Sample dilution in lysis buffer was performed for the final concentration within the range of the standard curve. BSA was dissolved with lysis buffer to a series of standard protein concentrations. Separate diluted sample $10 \mu \mathrm{L}$ (standard) reacted respectively with $300 \mu \mathrm{L}$ protein quantitation dye for $15 \sim 20 \mathrm{~min}$. Simultaneously, absorbance was measured and sample concentrations were calculated based on the standard curve [5].

\section{Enzymatic digestion of the proteins}

$100 \mu \mathrm{g}$ of total protein sample was used by a filter-aided sample preparation (FASP) protocol. Addition of $10 \mu \mathrm{L}$ of reducing reagent to the samples at $37^{\circ} \mathrm{C}$ for $1 \mathrm{~h}$ and $2 \mu \mathrm{L}$ of cysteine-blocking reagent for $30 \mathrm{~min}$ at room temperature followed. The reductive alkylated protein solution was then added to a $10 \mathrm{~K}$ ultrafiltration tube (Merck Millipore, REF UFC501096), centrifuged at 12, $000 \mathrm{rpm}$ for $20 \mathrm{~min}$, and bottom solution of the collection tube was discarded. Afterwards, $100 \mu \mathrm{L}$ dissolution buffer was added in the iTRAQ kit and centrifuged at $12,000 \mathrm{rpm}$ for $20 \mathrm{~min}$. Prior to collection tube replacement, the settled solution in the collection tube was discarded, and there were three repetitions. Subsequently,
$4 \mu \mathrm{g}$ (1:50 compared to protein) trypsin (Promega REF V5111) in a volume of $100 \mu \mathrm{L}$ was added and waited to react [5]. Sample centrifugation at $12,000 \mathrm{rpm}$ for $15 \mathrm{~min}$ was carried out on the following day. Subsequent to enzymatic digestion, the peptide solution was retained at the bottom of the collection tube. Ultrafiltration tube was used with $200 \mu \mathrm{L}$ of $\mathrm{ddH} 2 \mathrm{O}$ and centrifugation at $12,000 \mathrm{rpm}$ for $15 \mathrm{~min}$ followed. Resulting $500 \mu \mathrm{L}$ of the digested sample was collected from the collection tube.

\section{ITRAQ labeling}

iTRAQ reagent (8-plex) was set to reach room temperature. $150 \mu \mathrm{L}$ of isopropanol was added to each tube of iTRAQ reagent and vortexed to mix before centrifuged. A new centrifuge with $50 \mu \mathrm{L}$ of sample $(100 \mu \mathrm{g}$ of enzymatic product) was transferred, iTRAQ reagent was added, vortexed and centrifuged. $\mathrm{pH}$ testing followed with $0.5 \mu \mathrm{L}$ of the solution on $\mathrm{pH}$ paper of $\mathrm{pH}$ range 7.0 to 10.0 . The tubes were then incubated at room temperature for $2 \mathrm{~h}$. To stop the reaction, $100 \mu \mathrm{L}$ of ddH2O was added to the mixture.

\section{Offline pre-separation of enzymatically digested peptides and LC-MS/MS mass spectrometry}

After dissolving the labelled lyophilized peptides [5], the samples were centrifuged at $14,000 \mathrm{rpm}$ for $10 \mathrm{~min}$, and the supernatant was collected for use. Assessing the isolation conditions followed and $100 \mu \mathrm{L}$ of the total prepared sample was loaded at a flow rate of $0.7 \mathrm{~mL} / \mathrm{mins}$ and separation gradient were used [61]. Protein analysis and the nanoscale reversed-phase chromatography was facilitated by mass spectrometer (Thermo, Model: Fusion). The high $\mathrm{pH}$ reversed-phase resulting segments were reconstituted with $20 \mu \mathrm{L}$ ( $2 \%$ methanol, SigmaAldrich, article number: 14262, USA), (0.1\% formic acid, Sigma-Aldrich, Cat. No. 56302, USA), and 13,000 rpm centrifugation for $10 \mathrm{~min}$ followed. Loading by sandwich technique, isolation flow along with isolation gradients followed [60]. The mass spectroscopy (MS) parameter was set as: spray voltage $2.1 \mathrm{kV}$; capillary temperature: $250{ }^{\circ} \mathrm{C}$, and Scan range: $350-1800 \mathrm{~m} / \mathrm{z}$.

\section{Data analysis}

Bovine reference genome (ARS-UCD1.2) was used, and Fusion mass spectrometry was used for mass spectrometry analysis of iTRAQ. The original mass spectrometry data were processed uisng Thermo's commercial software Proteome Discoverer 1.4. Search parameters were used and Mascot facilitated an automated decoy database search by selecting the decoy checkbox [5]. The dataset collected proteins that existed in all three biological replicates. The observed findings were based on 95\% percent confidence intervals for protein recognition as calculated by a Mascot probability study. Proteins 
with confidence intervals greater than "identity" were considered to be known. At least one distinct peptide aided in protein recognition. Protein quantification was determined by proteins with at least two distinct spectra.

For protein quantification, it was required that a protein contains at least two unique spectra. MASCOT was used for Quantification protein ratios. The significant differentially abundant proteins (DAPs) were screened by T-test and proteins with a $p$-value less than 0.05 and a fold difference greater than 1.5 (Up regulated) or less than 0.67 (Down regulated) were considered DAPs.

\section{GO, KEGG and PPI analysis of DAPs}

Gene Ontology (GO) terms in the database (http://www. geneontology.org/) were used for mapping of the DAPs between yak and cattleyak epididymal tissues. Bonferroni Correction was used to normally adjust the $p$-value. Enrichment of biological pathways of the DAPs utilised KEGG database (Kyoto Encyclopedia of Genes and Genomes database). String Protein Interaction Database was used and the differential protein interaction network data files were complemented with Cytoscape software for visual editing.

\section{Enzyme linked immunosorbent assay (ELISA)}

ELISA confirmed eight differential abundance proteins, namely CD63, ELP3, LSM5, GSTM1, GGH, ERAP1, GPX5 and MUC15. The total protein of each sample was extracted according to the manufacture's protocol of DNA/RNA/protein co-extraction Kit (Tiangen Biotech (Beijing) Co., Ltd., China). The different sample protein concentration was detected by NanoDrop 3000 Spectrophotometer (Thermo Fisher Scientific, Wilmington, DE, USA) and adjusted to $0.1 \mathrm{mg} / \mathrm{mL}$. ELISA detection followed [5] and standard curve as well as regression equation were made using the manufacturer's standard samples with each sample analyzed with triplicates. Each well's OD value detection was noted using microplate reader, set to $450 \mathrm{~nm}$ within $15 \mathrm{~min}$. Using the regression equation, the targeted protein concentrations were calculated and each protein content was analyzed from each sample. Statistical analyses were performed using SPSS 22.0 standard version (IBM, Armonk, NY, USA). Student's t-test was employed to analyze differences of each protein expression level between the control (yak) and tested groups (cattleyak). For all tests, statistical significance was taken as $p<0.05$.

\footnotetext{
Abbreviations

AspRS: Aspartyl-tRNA synthetase; BVR A: Biliverdin reductase A; CAF-1: CCR4associated factor 1; DAPs: Differentially expressed proteins; ddH2O: Double distilled water; EECs: Epididymal epithelial cells; ELISA: Enzyme linked immunosorbent assay; ELP3: Elongator complex protein 3;

ERAP1: Endoplasmic reticulum aminopeptidase 1; FASP: Filter-aided sample preparation; GalNAc-T6: N-acetylgalactosaminyltransferase 6; GGH: Gammaglutamyl hydrolase; GO: Gene ontology; GPX5: Glutathione Peroxidase 5;
}

GSTM1: Glutathione S-transferase; iTRAQ: Isobaric tags for relative and absolute quantitation; KEGG Database : Kyoto Encyclopedia of Genes and Genomes database; MUC15: Mucin 15; NLS: Nuclear localization signal; PARP: Poly (ADP-ribose) polymerase; PCC: Protein-conducting channel; PEBP4: Phosphatidylethanolamine-binding protein 4; PTAC: Pore-targeting complex; RAP1: Ras- Proximate-1/ Ras- related protein 1; RNS: Reactive nitrogen species; ROS: Reactive oxygen species; SERPINA3: Serpin family A member 3; VAMP8: Vesicle-associated membrane protein 8; ZAG: Zinc-alpha2-glycoprotein

\section{Acknowledgements \\ Not applicable.}

\section{Authors' contributions}

WSZ: Methodology, Funding acquisition, SA: Formal analysis, Writing-Original Draft, JXL: Investigation, Formal analysis, SA: Validation, Data Curation, EQ: Software, Formal analysis, THS: Software, Validation, YTW: Visualization, Resources, YLYL: Investigation, Validation, HMW: Data Curation, Resources, JJZ: Writing-Review \& Editing, Conceptualization, XC: Supervision, Project administration. All authors have read and approved the final version of the manuscript.

\section{Funding}

The design and execution of the present study was financially supported by Sichuan Science and Technology Program (2021YFH0101). The analysis and interpretation of the data was funded by the National Natural Science Foundation of China (31601946) and Longshan Academic Talent Research Supporting Program of SWUST (17LZX671 and 18lzX661).

Availability of data and materials

All data included in this study are available upon request by contact with the corresponding author.

\section{Declarations}

\section{Ethics approval and consent to participate}

Sample collection was carried out under license in accordance with the Guidelines for Care and Use of Laboratory Animals of China and all protocols were approved by the Institutional Review Board of Southwest University of Science and Technology.

\section{Consent for publication}

Not applicable.

\section{Competing interests}

Not applicable.

\section{Author details}

${ }^{1}$ School of Life Science and Engineering, Southwest University of Science and Technology, Mianyang 621010, Sichuan, China. ${ }^{2}$ Qingdao Bright Moon Seaweed Group Co., Itd, Qingdao 266400, Shandong, China. ${ }^{3}$ Key Laboratory of Qinghai-Tibetan Plateau Animal Genetic Resource Reservation and Utilization (Southwest Minzu University), Ministry of Education, Chengdu 610041, Sichuan, China. ${ }^{4}$ Qinghai-Tibetan Plateau Animal Genetic Resource Reservation and Utilization Key Laboratory of Sichuan Province, Chengdu 610041, Sichuan, China.

Received: 12 November 2020 Accepted: 18 May 2021

Published online: 26 July 2021

\section{References}

1. Wang $H$, Long $R$, Liang JB, Guo X, Ding L, Shang Z. Comparison of nitrogen metabolism in yak (Bos grunniens) and indigenous cattle (Bos taurus) on the Qinghai-Tibetan plateau. Asian Australas J Anim Sci. 2011;24(6):766-73. https://doi.org/10.5713/ajas.2011.10350.

2. Li $X$, et al. Sequence analysis and study on the expression level of Dmc1 mRNA in yak and cattle-yak testis. Sci Agric Sin. 2010;43(15):3221-9.

3. Xu C, Wu S, Zhao W, Mipam TD, Liu J, Liu W, et al. Differentially expressed microRNAs between cattleyak and yak testis. Sci Rep. 2018;8(1):592. https:// doi.org/10.1038/s41598-017-18607-0. 
4. Sun $L$, et al. Comparative testis proteome of cattleyak from different developmental stages. Animal. 2017;11(1):101-11.

5. Yu S, Cai X, Sun L, Zuo Z, Mipam TD, Cao S, et al. Comparative iTRAQ proteomics revealed proteins associated with spermatogenic arrest of cattleyak. J Proteome. 2016;142:102-13. https://doi.org/10.1016/j.jprot.2016. 04.049.

6. Browne JA, Yang R, Leir SH, Eggener SE, Harris A. Expression profiles of human epididymis epithelial cells reveal the functional diversity of caput, corpus and cauda regions. MHR: Basic Sci Reprod Med. 2015;22(2):69-82. https://doi.org/10.1093/molehr/gav066.

7. Carroll M, Hamzeh M, Robaire B. Expression, localization, and regulation of inhibitor of DNA binding (id) proteins in the rat epididymis. J Androl. 2006 27(2):212-24. https://doi.org/10.2164/jandrol.05098.

8. Skerget S, Rosenow MA, Petritis K, Karr TL. Sperm proteome maturation in the mouse epididymis. PLoS One. 2015;10(11):e0140650. https://doi.org/1 0.1371/journal.pone.0140650

9. Wang $X$, et al. Comparative proteomic analysis of heat stress proteins associated with rat sperm maturation. Mol Med Rep. 2016;13(4):3547-52. https://doi.org/10.3892/mmr.2016.4958.

10. Nowicka-Bauer K, Kurpisz M. Current knowledge of the human sperm proteome. Expert Review Proteomics. 2013;10(6):591-605. https://doi.org/1 0.1586/14789450.2013.846221.

11. Chen X, Zhu H, Hu C, Hao H, Zhang J, Li K, et al. Identification of differentially expressed proteins in fresh and frozen-thawed boar spermatozoa by iTRAQ-coupled 2D LC-MS/MS. Reproduction. 2014;147(3): 321-30. https://doi.org/10.1530/REP-13-0313.

12. Zhu G, Cai G, Liu Y, Tan H, Yu C, Huang M, et al. Quantitative iTRAQ LC-MS/ MS proteomics reveals transcription factor crosstalk and regulatory networks in hypopharyngeal squamous cell carcinoma. J Cancer. 2014;5(7):525-36. https://doi.org/10.7150/jca.9207.

13. Ernoult E, Gamelin E, Guette C. Improved proteome coverage by using iTRAQ labelling and peptide OFFGEL fractionation. Proteome Sci. 2008;6(1): 27. https://doi.org/10.1186/1477-5956-6-27.

14. Chen J, Zhou A, Xie S, Wang C, Lv Z, Zou J. Comparative proteomic identification of mature and immature sperm in the catfish cranoglanis bouderius. PLoS One. 2016;11(3):e0151254. https://doi.org/10.1371/journal. pone.0151254.

15. Thimon V, Koukoui O, Calvo E, Sullivan R. Region-specific gene expression profiling along the human epididymis. Mol Hum Reprod. 2007;13(10):691704. https://doi.org/10.1093/molehr/gam051.

16. Yuan H, Liu A, Zhang L, Zhou H, Wang Y, Zhang H, et al. Proteomic profiling of regionalized proteins in rat epididymis indicates consistency between specialized distribution and protein functions. J Proteome Res. 2006;5(2): 299-307. https://doi.org/10.1021/pr050324s.

17. Somashekar L, Selvaraju S, Parthipan S, Patil SK, Binsila BK, Venkataswamy MM, et al. Comparative sperm protein profiling in bulls differing in fertility and identification of phosphatidylethanolamine-binding protein 4 , a potential fertility marker. Andrology. 2017;5(5):1032-51. https://doi.org/1 $0.1111 / a n d r .12404$

18. Chen H, Yang P, Chu X, Huang Y, Liu T, Zhang Q, et al. Cellular evidence for nano-scale exosome secretion and interactions with spermatozoa in the epididymis of the Chinese soft-shelled turtle, Pelodiscus sinensis. Oncotarget. 2016;7(15):19242-50. https://doi.org/10.18632/oncotarget.8092.

19. Ding Z, Qu F, Guo W, Ying X, Wu M, Zhang Y. Identification of sperm forward motility-related proteins in human seminal plasma. Mol Reprod Dev. 2007;74(9):1124-31. https://doi.org/10.1002/mrd.20624.

20. Shaha C, Gopalakrishnan B. Biological role of glutathione S-transferases on sperm. In: Gupta SK, editor. Reproductive immunology. Dordrecht: Springer; 1999. https://doi.org/10.1007/978-94-011-4197-0_2.

21. Gopalakrishnan B, et al. Studies on glutathione S-transferases important for sperm function: evidence of catalytic activity-independent functions. Biochem J. 1998;329(2):231-41. https://doi.org/10.1042/bj3290231.

22. Floehr, J., et al., Down-regulation of the liver-derived plasma protein fetuin-B mediates reversible female infertility. MHR: Basic science of reproductive medicine, 2016: 1-11.

23. Dietzel E, Wessling J, Floehr J, Schäfer C, Ensslen S, Denecke B, et al. FetuinB, a liver-derived plasma protein is essential for fertilization. Dev Cell. 2013; 25(1):106-12. https://doi.org/10.1016/j.devcel.2013.03.001.

24. Kamei Y, Yuba S, Nakayama T, Yoneda Y. Three distinct classes of the asubunit of the nuclear pore-targeting complex (importin-a) are differentially expressed in adult mouse tissues. J Histochem Cytochem. 1999;47(3):363-72. https://doi.org/10.1177/002215549904700310.

25. Tsuji $L$, Takumi T, Imamoto N, Yoneda $Y$. Identification of novel homologues of mouse importin a, the a subunit of the nuclear pore-targeting complex, and their tissue-specific expression. FEBS Lett. 1997;416(1):30-4. https://doi. org/10.1016/S0014-5793(97)01092-2.

26. Shyu M-K, Lin MC, Shih JC, Lee CN, Huang J, Liao CH, et al. Mucin 15 is expressed in human placenta and suppresses invasion of trophoblast-like cells in vitro. Hum Reprod. 2007;22(10):2723-32. https://doi.org/10.1093/ humrep/dem249.

27. Brancolini C, Bottega S, Schneider C. Gas2, a growth arrest-specific protein, is a component of the microfilament network system. J Cell Biol. 1992; 117(6):1251-61. https://doi.org/10.1083/jcb.117.6.1251.

28. Brancolini C, Schneider C. Phosphorylation of the growth arrest-specific protein Gas2 is coupled to actin rearrangements during go--> G1 transition in NIH 3T3 cells. J Cell Biol. 1994;124(5):743-56. https://doi.org/10.1083/ jcb.124.5.743.

29. Sezgin G, Dabak R, Kaya FO, Kotevoglu N, Uygur-Bayramiçli O, Nalbant S. The association of endoplasmic reticulum aminopeptidase-1 (ERAP-1) with familial Mediterranean fever (FMF). United European Gastroenterol J. 2016; 4(1):92-6. https://doi.org/10.1177/2050640615584536

30. Goto $Y$, et al. Acute-phase protein-like properties of endoplasmic reticulum aminopeptidase 1. J Biochem. 2018;165(2):159-65.

31. Weise J, Isenmann S, Bähr M. Increased expression and activation of poly (ADP-ribose) polymerase (PARP) contribute to retinal ganglion cell death following rat optic nerve transection. Cell Death Differ. 2001;8(8):801-7. https://doi.org/10.1038/sj.cdd.4400872.

32. Agarwal A, Mahfouz RZ, Sharma RK, Sarkar O, Mangrola D, Mathur PP. Potential biological role of poly (ADP-ribose) polymerase (PARP) in male gametes. Reprod Biol Endocrinol. 2009;7(1):143. https://doi.org/10.1186/1477-7827-7-143.

33. Thies RL. Reactive oxygen injury to cultured pulmonary artery endothelial cells: mediation by poly (ADP-ribose) polymerase activation causing NAD depletion and altered energy balance. Arch Biochem Biophys. 1991;286(2): 353-63. https://doi.org/10.1016/0003-9861(91)90051-J.

34. Chandra A, Srinivasan KR, Jamal F, Mehrotra PK, Singh RL, Srivastav A. Posttranslational modifications in glycosylation status during epididymal passage and significance in fertility of a $33 \mathrm{kDa}$ glycoprotein (MEF3) of rhesus monkey (Macaca mulatta). Reproduction. 2008;135(6):761-70. https://doi.org/10.1530/REP-07-0525.

35. Li Z, Yamada S, Inenaga S, Imamura T, Wu Y, Wang KY, et al. Polypeptide $\mathrm{N}$-acetylgalactosaminyltransferase 6 expression in pancreatic cancer is an independent prognostic factor indicating better overall survival. $\mathrm{Br} J$ Cancer. 2011;104(12):1882-9. https://doi.org/10.1038/bjc.2011.166.

36. Tulsiani DRP, Skudlarek MD, Holland MK, Orgebin-Crist MC. Glycosylation of rat sperm plasma membrane during epididymal maturation. Biol Reprod. 1993;48(2):417-28. https://doi.org/10.1095/biolreprod48.2.417.

37. Srivastava A, Olson GE. Glycoprotein changes in the rat sperm plasma membrane during maturation in the epididymis. Mol Reprod Dev. 1991; 29(4):357-64. https://doi.org/10.1002/mrd.1080290407.

38. Cesari A, et al. Regulated serine proteinase lytic system on mammalian sperm surface: There must be a role. Theriogenol. 2010;74(5):699-711 e5.

39. Balestrieri ML, et al. Proteomic profiles of the embryonic chorioamnion and uterine caruncles in buffaloes (Bubalus bubalis) with normal and retarded embryonic development. Biol Reprod. 2013;88(5):119 1-14.

40. O'rand $\mathrm{M}$, et al. Reversible immunocontraception in male monkeys immunized with eppin. Science. 2004;306(5699):1189-90. https://doi.org/1 0.1126/science.1099743.

41. Rodríguez CM, Kirby $J$, Hinton BT. Regulation of gene transcription in the epididymis. Reproduction-Cambridge. 2001;122(1):41-8. https://doi.org/10.1 530/rep.0.1220041.

42. $\mathrm{Li} \mathrm{Z}$, Kono H. Distinct roles of histone $\mathrm{H} 3$ and $\mathrm{H} 2 \mathrm{~A}$ tails in nucleosome stability. Sci Rep. 2016;6(1):31437. https://doi.org/10.1038/srep31437.

43. Gaspar-Maia A, Qadeer ZA, Hasson D, Ratnakumar K, Adrian Leu N, Leroy G, et al. MacroH2A histone variants act as a barrier upon reprogramming towards pluripotency. Nat Commun. 2013;4(1):1565. https://doi.org/10.1038/ ncomms2582.

44. Saurabh S, Glaser MA, Lansac Y, Maiti PK. Atomistic simulation of stacked nucleosome core particles: tail bridging, the $\mathrm{H} 4$ tail, and effect of hydrophobic forces. J Phys Chem B. 2016;120(12):3048-60. https://doi.org/1 $0.1021 / a c s . j p c b .5 b 11863$ 
45. Vogler C, Huber C, Waldmann T, Ettig R, Braun L, Izzo A, et al. Histone H2A $\mathrm{C}$-terminus regulates chromatin dynamics, remodeling, and histone $\mathrm{H} 1$ binding. PLoS Genet. 2010;6(12):e1001234. https://doi.org/10.1371/journal. pgen.1001234

46. DeFraia C, Mou Z. The role of the Elongator complex in plants. Plant Signal Behav. 2011;6(1):19-22. https://doi.org/10.4161/psb.6.1.14040.

47. Liyanage V, Jarmasz J, Murugeshan N, del Bigio M, Rastegar M, Davie J. DNA modifications: function and applications in normal and disease states. Biology. 2014;3(4):670-723. https://doi.org/10.3390/biology3040670.

48. Aslam A, Mittal S, Koch F, Andrau JC, Winkler GS. The Ccr4-NOT deadenylase subunits CNOT7 and CNOT8 have overlapping roles and modulate cell proliferation. Mol Biol Cell. 2009;20(17):3840-50. https://doi. org/10.1091/mbc.e09-02-0146.

49. Greenberg ME, Belasco JG. Control of Messenger RNA Stability. San Diego: Academic Press; 1993:199-217.

50. Chen CYA, Shyu AB. Deadenylation and P-bodies, in Ten years of progress in GW/P body research. Springer; 2013. p. 183-195.

51. Hardin JW, Warnasooriya C, Kondo Y, Nagai K, Rueda D. Assembly and dynamics of the U4/U6 di-snRNP by single-molecule FRET. Nucleic Acids Res. 2015;43(22):10963-74. https://doi.org/10.1093/nar/gkv1011.

52. Wang $Y$, et al. Mechanism of alternative splicing and its regulation. Biomed Reports. 2015;3(2):152-8. https://doi.org/10.3892/br.2014.407.

53. Ni H, Lu L, Deng J, Fan W, Li T, Yao J. Effects of glutamate and aspartate on serum antioxidative enzyme, sex hormones, and genital inflammation in boars challenged with hydrogen peroxide. Mediat Inflamm. 2016;2016:1-10. https://doi.org/10.1155/2016/4394695.

54. Gogala M, Becker T, Beatrix B, Armache JP, Barrio-Garcia C, Berninghausen O, et al. Structures of the Sec61 complex engaged in nascent peptide translocation or membrane insertion. Nature. 2014;506(7486):107-10. https:// doi.org/10.1038/nature12950.

55. Kumar L, Yadav SK, Kushwaha B, Pandey A, Sharma V, Verma V, et al. Energy utilization for survival and fertilization-parsimonious quiescent sperm turn extravagant on motility activation in rat. Biol Reprod. 2016;94(4):96, 1-9. https://doi.org/10.1095/biolreprod.115.137752.

56. D'Amours O, Frenette G, Caron P, Belleannée C, Guillemette C, Sullivan R. Evidences of biological functions of biliverdin reductase $\mathrm{a}$ in the bovine epididymis. J Cell Physiol. 2016;231(5):1077-89. https:/doi.org/10.1002/jcp.25200.

57. Kaur H, Hughes MN, Green CJ, Naughton P, Foresti R, Motterlini R. Interaction of bilirubin and biliverdin with reactive nitrogen species. FEBS Lett. 2003;543(1-3):113-9. https://doi.org/10.1016/S0014-5793(03)00420-4.

58. Cheah $Y$, Yang $W$. Functions of essential nutrition for high quality spermatogenesis. Adv Biosci Biotechnol. 2011;2(04):182-97. https://doi.org/1 0.4236/abb.2011.24029.

59. Schneider E, Ryan TJ. Gamma-glutamyl hydrolase and drug resistance. Clin Chim Acta. 2006;374(1-2):25-32. https://doi.org/10.1016/j.cca.2006.05.044.

60. Zhao W, Quansah E, Yuan M, Gou Q, Mengal K, Li P, et al. Region-specific gene expression in the epididymis of yak. Theriogenology. 2019;139:132-46. https://doi.org/10.1016/.theriogenology.2019.08.006.

61. Yang T, Jia Y, Ma Y, Cao L, Chen X, Qiao B. Comparative proteomic analysis of bleomycin-induced pulmonary fibrosis based on isobaric tag for quantitation. Am J Med Sci. 2017;353(1):49-58. https://doi.org/10.1016/j.amjms.2016.11.021.

\section{Publisher's Note}

Springer Nature remains neutral with regard to jurisdictional claims in published maps and institutional affiliations.

Ready to submit your research? Choose BMC and benefit from:

- fast, convenient online submission

- thorough peer review by experienced researchers in your field

- rapid publication on acceptance

- support for research data, including large and complex data types

- gold Open Access which fosters wider collaboration and increased citations

- maximum visibility for your research: over $100 \mathrm{M}$ website views per year

At BMC, research is always in progress.

Learn more biomedcentral.com/submissions 